\title{
O ensino de Ciências com base no conhecimento tradicional sobre plantas medicinais
}

Science teaching based on traditional knowledge about medicinal plants

\author{
Eloisa Basso ${ }^{1}$ \\ Aline Locatelli \\ Cleci Teresinha Werner da Rosa ${ }^{3}$
}

\section{Resumo}

O presente estudo parte da premissa de que alguns aspectos da cultura vêm se perdendo entre muitos estudantes indígenas, como, por exemplo, os conhecimentos que são passados de geração em geração. Em relação a valorização dos conhecimentos tradicionais e à importância de serem trazidos para as salas de aula, realizou-se uma pesquisa com 49 estudantes indígenas das séries finais do Ensino Fundamental, sobre os saberes envolvendo plantas medicinais. A partir dos resultados da pesquisa foram elencadas seis plantas medicinais, a saber: bananeira, laranjeira, pinheiro-do-paraná, camomila, calêndula e citronela e apresentamos neste artigo as possibilidades de abordagens de conceitos/conteúdos de Ciências, à luz da Base Nacional Comum Curricular (BNCC), no sentido de apresentar quais seriam as unidades temáticas, os objetos do conhecimento e as habilidades vinculadas a cada uma das plantas medicinais especificadas.

Palavras chave: BNCC; estudantes indígenas; ensino fundamental.

\section{Abstract}

The current research is about the assumption that some aspects of the culture has been lost among many indigenous students, as for example, the knowledge that is passed through generations. In relation to this traditional knowledge and the importance of being brought to the classroom, a survey was carried out with 49 indigenous students of the final years of Elementary School, on knowledge involving medicinal plants. From the research results, six medicinal plants were listed, namely: banana, orange, Paraná pine, chamomile, marigold and citronella and we present in this article the possibilities of approaches the contents of Science, in the light of the Brazilian National Curriculum (BNCC), in order to present the thematic units, the objects of knowledge and the skills linked to each of the specified medicinal plants.

Keywords: BNCC; indigenous students; elementary school.

\footnotetext{
${ }^{1}$ Universidade de Passo Fundo | elobasso@yahoo.com.br

${ }^{2}$ Universidade de Passo Fundo | alinelocatelli@upf.br

${ }^{3}$ Universidade de Passo Fundo | cwerner@upf.br
} 


\section{Introdução}

O ensino de Ciências é capaz de envolver situações diretamente relacionadas com os saberes populares de uma comunidade, além de contribuir para a aprendizagem dos alunos, ainda os desafiar a irem em busca de explicações para as mais diversas situações (CHASSOT, 2008). Nesse sentido, a escola é vista como um ambiente apto de trabalhar com um ensino capaz de despertar o interesse pela busca da valorização dos saberes que vem se perdendo, principalmente entre os jovens indígenas no que se refere aos conhecimentos acerca do uso das plantas medicinais, enfatizando a sua importância dentro de tais comunidades.

A possibilidade de desenvolver propostas didáticas que valorizam o conhecimento de um povo, visando ao fortalecimento de suas identidades, além de permitir uma maior aproximação dos conteúdos de Ciências com a vida cotidiana, também contribui para uma aprendizagem mais significativa, na qual o estudante passa a ver sentido naquilo que está aprendendo ao ponto de compreender a importância da disciplina de Ciências, principalmente quando essa for abordada considerando o contexto social de tais estudantes.

Entretanto, desenvolver um trabalho na perspectiva de valorização do saber popular e local da comunidade onde a escola está localizada não é algo tão fácil, devido à validação do conhecimento científico pelas instituições de pesquisa e pela própria escola que o consideram como algo verdadeiro e suficiente para a aprendizagem do aluno em detrimento do conhecimento popular (VENQUIARUTO; DALLAGO; VANZETO; DEL PINO, 2011).

Além disso, a escola está acostumada a transmitir o conhecimento científico, sendo que ela não o produziu e se for convidada a trabalhar com os saberes que são próprios da comunidade onde está inserida, certamente, vai se renegar, pois não possui esse conhecimento. Mesmo existindo uma diferença entre o produzir e o transmitir, a escola não se diminui por ser apenas transmissora do saber, desde que o faça dentro de uma maneira contextualizada (CHASSOT, 2001).

No entanto, é necessário que a escola desenvolva um trabalho em benefício da valorização do saber popular de forma contextualizada com as disciplinas do currículo, sendo que, esse conhecimento irá proporcionar uma conscientização quanto ao respeito à comunidade e ao contexto social ao qual essa instituição está inserida e "esta é uma função da escola, e é tanto uma função pedagógica como uma função política: a defesa dos saberes da comunidade onde ela está inserida" (CHASSOT, 2001, p. 211).

Nesse sentido, ao pensarmos na construção do conhecimento, por meio do diálogo entre o saber popular e o saber científico, o ensino não pode mais estar centrado apenas na transmissão dos conteúdos presentes no livro didático, ou na situação em que o aluno escuta e aceita as explicações do professor como sendo únicas e verdadeiras (VENQUIARUTO; DALLAGO; VANZETO; DEL PINO, 2011).

É necessário que se utilizem novas estratégias metodológicas de ensino que estejam de acordo com a realidade dos alunos, e que despertem a curiosidade e o interesse, para que ocorra uma aprendizagem mais significativa, a fim de transformá-los em pessoas capazes de exercer uma cidadania cada vez mais crítica na sociedade em que vivem.

Dessa forma, ao pensar na educação indígena, é preciso considerar a cultura desse povo que detêm um acervo de saberes tradicionais que foram construídos empiricamente ao longo dos anos pela observação e experimentação. Tais saberes implicam numa escola 
capaz de trabalhar o conhecimento científico, com base nas concepções indígenas do mundo, considerando a sua organização social e cultural (RCNEl, 1998).

No que se refere ao ensino de Ciências, para o Ensino Fundamental, na Base Nacional Comum Curricular (BNCC) é mencionado que o ensino das Ciências deve ocorrer na articulação com outros campos de saber e que "precisa assegurar aos alunos do Ensino Fundamental o acesso à diversidade de conhecimentos científicos produzidos ao longo da história, bem como a aproximação gradativa aos principais processos, práticas e procedimentos da investigação científica" (BRASIL, 2017, p. 319).

No que se refere mais especificamente à Educação Indígena, a BNCC aponta que é importante

[...] assegurar competências específicas com base nos princípios da coletividade, reciprocidade, integralidade, espiritualidade e alteridade indígena, a serem desenvolvidas a partir de suas culturas tradicionais reconhecidas nos currículos dos sistemas de ensino e propostas pedagógicas das instituições escolares (BRASIL, 2017, p. 17, grifo nosso).

Dessa forma, tendo em vista que as plantas medicinais fazem parte dos conhecimentos tradicionais da cultura indígena e que estudos apontam que a utilização dessas plantas na cura de doenças vem se perdendo entre os jovens da comunidade, surge o interesse em trabalhar com esse assunto, por meio do desenvolvimento de um estudo no qual tem como objeto de estudo os conhecimentos tradicionais sobre plantas medicinais, e de que forma os conceitos/conteúdos de Ciências correlatos estão alinhados com a nova BNCC.

\section{Conhecimento Científico, Saber Popular e/ou Conhecimento Tradicional}

É comum encontrar alunos que consideram a Ciência como uma disciplina qualquer e sem importância. E um dos motivos que explica esse desinteresse pode estar associado à imagem que eles construíram da disciplina, restrita à sala de aula, distante da sua realidade, a qual é trabalhada por meio de textos, fórmulas e exercícios, que pouco ou nada significam, sendo esses obrigados a aceitar aquilo que Ihes é transmitido, acreditando ter entendido (FIGARO, 2015).

Situações desse tipo também podem ser vistas em escolas nas quais a prática docente está centrada no ensino mecânico, no qual o professor apenas reproduz o conteúdo do livro didático pronto e acabado, ao acreditar que, "se o educador é o que sabe, se os educandos são o que nada sabem, cabe àquele dar, entregar, levar, transmitir o seu saber aos segundos. Saber que deixa de ser de "experiência feito" para ser de experiência narrada ou transmitida" (FREIRE, 1987, p. 34). Paulo Freire, em seu livro Pedagogia do Oprimido, enfatiza a questão da educação bancária, a qual deve ser superada, pois, quanto mais o professor insistir em ensinar conteúdos desconectados da realidade, mais o aluno(a) estará se tornando ingênuo e passivo ao invés de agir como sujeito ativo do processo de ensinoaprendizagem, pelo fato de não ver sentido naquilo que está sendo obrigado a aprender.

Entretanto, pelo fato de morarmos em um país que abrange uma enorme diversidade cultural, uma possibilidade, seria considerar essas especificidades na prática educacional, por meio de um ensino que valorize o saber popular e/ou saber tradicional, vindos das famílias e das comunidades em que os estudantes pertencem, a fim de tornar a 
aprendizagem mais significativa, de forma que esses consigam entender a relação que existe entre a ciência e o seu dia a dia (GONDIM; MÓL, 2009). É preciso que o educador compreenda a importância "de levar em consideração a existência do "aqui" do educando", respeitando-o, pois, não é possível "negar os "saberes de experiência feitos" com que os educandos chegam à escola" (FREIRE, 1997, p. 31), ou seja, aqueles conhecimentos que permeiam a vivência das famílias dos nossos estudantes, sendo esses, na maioria das vezes, os únicos recursos disponíveis na manutenção da vida desses indivíduos que sobrevivem à mercê de condições precárias de acesso a condições mais dignas e facilitadoras do trabalho e da subsistência.

Dessa forma, a abordagem dos conceitos científicos com base no saber popular e/ou saber tradicional dos estudantes, utilizando situações problemas que envolvam os conhecimentos prévios e as metodologias alternativas que despertem a curiosidade e o interesse é uma alternativa a ser considerada pelas escolas como estratégia pedagógica, durante o planejamento e a realização das atividades (FIGARO, 2015).

Ao relacionar os conteúdos científicos com os conhecimentos que os alunos já detêm, o professor estará contribuindo para que eles percebam que a ciência está presente em sua vida cotidiana de uma forma lúdica e, por meio dessa compreensão, espera-se que o estudante desenvolva um pensamento crítico e consiga demonstrar atitudes mais conscientes perante a sociedade (FIGARO, 2015). "Isto significa, em última análise, que não é possivel ao(a) educador(a) desconhecer, subestimar ou negar os "saberes de experiência feitos" com que os educandos chegam à escola" (FREIRE, 1997, p. 31).

Segundo Chassot (2003, p. 94), a ideia da valorização dos saberes populares de forma a preservá-los, dando espaço e aproveitando-os em sala de aula, transformando-os em saberes escolares, deve ser considerada, pois é comum ocorrer entre os mais jovens um forte "presenteísmo (vinculação exclusiva ao presente, sem enraizamento com o passado e sem perspectivas para o futuro) e ao cientificismo (crença exagerada no poder da ciência e/ou atribuição à mesma de efeitos apenas benéficos)". Contudo, para tentar fazer uma oposição a esse cientificismo, que ainda se encontra tão presentes nos dias atuais, especialmente em nossas salas de aula, inclusive nas universidades, é necessário fazer com que o aluno entenda que o conhecimento científico é apenas uma "linguagem para facilitar a nossa leitura de mundo", porém, "mutável e falível" (CHASSOT, 2001, p. 37).

Para O autor, "os saberes populares são os muitos conhecimentos produzidos solidariamente e, às vezes, com muita empiria" e um dos exemplos que pode ser apontado, dentre outros, é o da medicina popular, na qual se encontram especialistas em traumatologia, os tão populares consertadores de ossos de nosso meio rural (CHASSOT, 2001, p. 205).

Ainda, de acordo com o mesmo autor (2001, p. 207) "O saber popular é aquele que detém, socialmente, o menor prestígio, isto é, o que resiste a menos códigos. Aliás, popular pode significar vulgar, trivial, plebeu". Contudo, é preciso recordar que esse saber popular, em algum momento da existência, foi/é/será um saber científico. Já, autores como Xavier e Flôr (2015, p. 310) consideram "os saberes populares como um conjunto de conhecimentos elaborados por pequenos grupos (famílias, comunidades), fundamentados em experiências ou em crenças e superstições, e transmitidos de um indivíduo para outro, principalmente por meio da linguagem oral e dos gestos".

Para Lopes (1993, p.18), o saber popular é produzido por grupos específicos, não permeando a sociedade como um todo, o qual "aponta para a especificidade e para a 
diversidade". Nele, pode-se considerar o saber das classes populares com respeito às ervas medicinais, à construção de casas, à culinária, aos diferentes tipos de artesanatos, muitos deles associados à produção de artefatos para o trabalho. São conhecimentos que permitem ao grupo viver melhor, mas não têm a função de orientação, como o senso comum, o qual por outro viés, compreende aqueles saberes que guiam os homens, independentemente de grupo ou classe social. O saber popular é, portanto, múltiplo, no sentido que é diferente para cada comunidade, "enquanto o senso comum aponta para a universalidade e para a uniformidade" (LOPES, 1993, p.18). Todavia, para Fonseca (2002, p. 10), "O senso comum é uma forma específica de conhecimento", o qual surgiu da necessidade de se resolver problemas imediatos da nossa vida, por meio de ações não planejadas, opiniões, emoções e valores particulares da sociedade que o originou. Sendo assim, o senso comum, pode variar de acordo com o momento e o conhecimento das pessoas envolvidas.

Já para Bastos (2013, p. 4),

[...] esses saberes populares também chamados de senso-comum ou saberes da tradição representam a manifestação de um conhecimento que não está escrito nos livros. As receitas de remédios, as rezas e seus gestos, bem como a sensibilidade para perceber as nuances do comportamento da criança são conhecimentos que não se aprendem na escola, não existem nos manuais ou nos livros, eles são repassados oralmente ao longo das gerações ao longo dos tempos. São conhecimentos esquecidos, abandonados, subjugados por um conhecimento considerado superior e vivem à margem do que, modernamente, chamamos ciência.

Normalmente, as pessoas que são detentoras de saberes popular e de conhecimentos tradicionais, sentem-se à vontade para falar a respeito do que sabem, pois, essas consideram que tais conhecimentos, por terem sido produzidos coletivamente, pertencem à comunidade e não apenas a um único indivíduo, sendo que a principal maneira de se obter esses conhecimentos é por meio da troca de experiências com os mais velhos e por meio de longas conversas. Entretanto, esses valiosos conhecimentos correm o risco de desaparecer, devido às novas tecnologias que vêm, dia após dia, se apossando do patrimônio genético brasileiro, como é o caso da indústria farmacêutica que extraí matéria prima das nossas florestas para utilizá-las na fabricação de medicamentos, cosméticos e outros, ou pelo fato de a ciência não saber explicar algumas áreas do conhecimento como a meteorologia e a astrologia, as quais passam a desmerecer credibilidade, por não serem alvo de interesse dos pesquisadores (CHASSOT, 2001).

$\mathrm{Na}$ concepção de Santilli (2008), os conhecimentos tradicionais são aqueles conhecimentos ou práticas que foram produzidos e estão associados ao ambiente no qual vivem as comunidades detentoras de tais saberes, sendo os povos indígenas, um exemplo dessas comunidades. Esses conhecimentos e práticas dos povos tradicionais "incluem desde propriedades medicinais de espécies animais até técnicas de manejo de recursos naturais, métodos de caça e pesca, conhecimentos sobre os diversos ecossistemas e até as próprias categorizações e classificações de fauna e flora" (p. 168). Contudo, muitos desses conhecimentos, ao saírem das aldeias, se tornam populares nas grandes cidades.

De outro modo, na concepção de Diegues, Arruda, Silva, Figols e Andrade (1999), o "conhecimento tradicional é definido como o conjunto de saberes e saber-fazer a respeito 
do mundo natural, sobrenatural, transmitido oralmente de geração em geração", (p. 33), que permeia entre as sociedades tradicionais, as quais são definidas pelos autores como

[...] grupos humanos culturalmente diferenciados que historicamente reproduzem seu modo de vida, de forma mais ou menos isolada, com base em modos de cooperação social e formas específicas de relações com a natureza, caracterizados tradicionalmente pelo manejo sustentado do meio ambiente (p. 25).

Além dos povos indígenas, tal definição também poderá ser mencionada para outras populações, dentre elas, caiçaras, sitiantes, roceiros, quilombolas, ribeirinhos, pescadores e extrativistas, os quais desenvolveram modos particulares de sobrevivência adaptados às condições ambientais disponíveis dentro de cada comunidade em particular, além de contribuir para a manutenção da biodiversidade dos ecossistemas, definida pela Convenção sobre a Diversidade Biológica (CDB), em seu artigo $2^{\circ}$, como

[...] a variabilidade de organismos vivos de todas as origens, compreendendo, dentre outros, os ecossistemas terrestres, marinhos e outros ecossistemas aquáticos e os complexos ecológicos de que fazem parte; compreendendo ainda a diversidade dentro de espécies, entre espécies e de ecossistemas (DIAS, 2000, p. 11).

A preservação de tais espécies é indispensável para assegurar o fornecimento de alimentos e matéria prima para o desenvolvimento de pesquisas científicas e a produção de insumos farmacêuticos e industriais (DIEGUES; ARRUDA; SILVA; FIGOLS; ANDRADE, 1999). Em relação à legislação, o conceito dos povos e comunidades tradicionais, encontra-se no artigo $3^{\circ}$ do Decreto no 6040, de 7 de fevereiro de 2007 (BRASIL, 2007). De acordo com este decreto, tais povos e comunidades são

[...] grupos culturalmente diferenciados e que se reconhecem como tais, que possuem formas próprias de organização social, que ocupam e usam territórios e recursos naturais como condição para sua reprodução cultural, social, religiosa, ancestral e econômica, utilizando conhecimentos, inovações e práticas gerados e transmitidos pela tradição.

Para os povos tradicionais, os recursos biológicos encontrados na natureza, não representam apenas um produto com função utilitária para fins concretos, como, por exemplo, a obtenção do conhecimento a respeito das propriedades medicinais de algumas plantas para utilizá-las no tratamento de doenças ou até mesmo o conhecimento nutricional de tais plantas para cultivá-las e utilizá-las na alimentação. Mais do que isso, para os povos tradicionais, os recursos da diversidade biológica têm, "um valor simbólico e espiritual" (SANTILLI, 2008, p. 168), os quais permeiam as características que fazem parte da cultura e tradição desses povos e que vão além da dimensão econômica, a qual engloba, dentre outros exemplos, o sistema de patentes, as quais protegem "os chamados conhecimentos novos, individualmente produzidos", por meio da extração de princípios ativos que são retirados de plantas, presentes nesses locais, e que apresentam características farmacológicas, passíveis de aplicação industrial direta, relacionada à produção de medicamentos (SANTILLI, 2008, p. 169).

Contudo, o sistema de patentes não oferece nenhuma proteção aos conhecimentos gerados pelos povos e comunidades tradicionais, os quais foram "produzidos 
coletivamente, que não têm uma origem precisa no tempo, e são transmitidos, pela via oral, às novas e sucessivas gerações" (SANTILLI, 2008, p. 169), pois ao contrário desses, tal sistema "promove uma fragmentação dos conhecimentos e a dissociação dos contextos culturais em que são produzidos" (p. 169).

Dessa forma, a fim de preservar o patrimônio genético brasileiro bem como a integridade intelectual e cultural associados aos conhecimentos tradicionais, já é prevista em lei a proteção aos conhecimentos de comunidades tradicionais relevantes à conservação da diversidade biológica. A CBD reconhece já em seu prefácio, "a estreita e tradicional dependência de recursos biológicos de muitas comunidades locais e populações indígenas com estilos de vida tradicionais" (DIAS, 2000, p. 8). Além disso, a referida convenção, em seu artigo 8, estabelece que os países subscritores devem

[...] respeitar, preservar e manter o conhecimento, inovaç̃̃es e práticas das comunidades locais e populações indígenas com estilo de vida tradicionais relevantes à conservação e à utilização sustentável da diversidade biológica e incentivar sua mais ampla aplicação com a aprovação e a participação dos detentores desse conhecimento, inovações e práticas [...] encorajar a repartição equitativa dos benefícios oriundos da utilização desse conhecimento, inovaç̃̃es e práticas (DIAS, 2000, p. 12).

Entretanto, para que isso de fato ocorra, é necessária a construção de um regime jurídico sui generis de proteção aos conhecimentos tradicionais associados à biodiversidade, o qual reconhece a coletividade sobre os direitos intelectuais associados aos conhecimentos tradicionais. Todavia,

[...] sem a tutela efetiva aos territórios ocupados por povos indígenas, quilombolas e populações tradicionais, e aos recursos naturais neles existentes, e sem a adoção de políticas públicas que promovam e assegurem direitos econômicos, sociais e culturais, será impossível assegurar a continuidade da produção dos conhecimentos tradicionais associados à biodiversidade (SANTILLI, 2008, p. 173).

Além disso, as políticas públicas devem promover um tratamento igualitário entre o conhecimento científico e saber tradicional, "reconhecendo que os sistemas tradicionais de conhecimentos têm os próprios fundamentos científicos e epistemológicos" (SANTILLI, 2008, p. 173), pois ainda, de acordo com o referido autor, tal conhecimento não é estático, e sim dinâmico, que se transforma e evolui ao longo das gerações.

No entanto, tais conhecimentos tradicionais que foram "produzidos e gerados de forma coletiva, a partir de ampla troca e circulação de ideias e informações, e transmitidos oralmente, de uma geração à outra", (SANTILLI, 2004, p. 11), "reportam-se a referenciais culturais coletivos" (SANTILLI, 2008, p. 175). Esses conhecimentos que poderão ser compartilhados por mais de um povo indígena, também podem apresentar algumas especificidades, como no caso dos usos medicinais de algumas espécies que só os pajés dominam ou conhecimentos tradicionais sobre uma mesma espécie, que pode variar quanto às formas de preparo e uso, bem como as suas propriedades, dependendo do local onde essa for utilizada com fins terapêuticos. Dessa forma, "a atribuição de direitos intelectuais coletivos a um único povo, ou mesmo a uma ou mais comunidades, pode excluir outros codetentores, gerando uma lógica de concorrência e rivalidades", a qual se 
faz necessário evitar, pois, a concorrência e exclusão não condizem com a forma como esses conhecimentos tradicionais foram gerados (SANTILLI, 2008, p. 176).

De outro modo, é importante destacar que os conhecimentos das populações tradicionais também têm sido objeto de pesquisas na área farmacêutica e industrial, as quais buscam alcançar resultados no desenvolvimento de novos produtos comerciais, pois tais conhecimentos podem ser um indicativo de que determinadas espécies apresentam propriedades farmacêuticas, alimentícias e agrícolas. Em relação à indústria farmacêutica, dentre os princípios ativos isolados de plantas nos últimos anos e que são "largamente utilizados na medicina moderna, 75\% têm utilidades que foram identificadas pelos sistemas tradicionais". Desses, a menor parte foi sintetizada por modificações químicas simples e o restante é apenas extraído e purificado (SHIVA, 2001 apud SANTILLI, 2004, p. 4).

Entretanto, apesar de toda a riqueza natural que o Brasil possui, ainda considera-se baixa a "exploração e utilização dos recursos genéticos que fazem parte da biodiversidade brasileira" (RIGDEN; CAVALCANTI; WALTER, 2008, p. 158), sendo que a utilização desses recursos é de grande relevância para o desenvolvimento econômico do país, por apresentarem um alto potencial de uso, "especialmente no que diz respeito às novas alternativas de alimentação e de produtos medicinais" (RIGDEN; CAVALCANTI; WALTER, 2008, p. 158).

Assim sendo, com o objetivo de se obter informações sobre plantas potencialmente importantes, estudos etnobotânicos também vêm sendo desenvolvidos nos últimos anos. Tais estudos podem fornecer informações valiosas sobre o conhecimento popular das comunidades tradicionais (raizeiros, curandeiros) e indígenas, em relação a espécies consideradas medicinais, as quais "possuem princípios ativos que coadunam com o uso popular que Ihes é atribuído", (RIGDEN; CAVALCANTI; WALTER, 2008, p. 160), os quais também têm contribuído para a produção em escala industrial de medicamentos, alimentos e outros produtos de valor econômico e que são de interesse do mercado nacional e internacional.

Já, segundo Bastos (2013, p. 6197), com o intuito de compreender como ocorre o processo de interação entre as populações humanas e os seus recursos naturais,

[...] os estudos em etnociências têm como objeto de investigação o repertório de conhecimentos, saberes e práticas dos povos tradicionais (indígenas, caboclos, ribeirinhos, seringueiros, quilombos, entre outros) em um movimento de documentação, estudo e valorização de suas culturas.

Saber como tais grupos vêm organizando o seu saber, ou a sua medicina, para a qual desenvolveram uma verdadeira "enciclopédia" de plantas consideradas milagrosas, "raízes cujo chá cura, ao mesmo tempo, câncer e dores de amor desfeito; ervas que combatem a impotência masculina. Folhas especiais para o resguardo da parturiente, para a "espinhela caída" etc.". (FREIRE, 1997, p. 69). Além disso, na concepção de Freire, tais estudos "podem ajudar as classes populares a ganhar confiança em si ou a aumentar o grau de confiança em que já se achem", pois independentemente do local onde o aluno se encontra, é extremamente importante a compreensão do mundo que o cerca, e a confiança em si mesmo, "tão indispensável à sua luta por um mundo melhor" (FREIRE, 1997, p. 69).

Contudo, usar o conhecimento tradicional brasileiro e o patrimônio genético, para fins industriais "sem um critério que propicia uma contrapartida para os brasileiros, é um dos desafios do século atual" (RIGDEN; CAVALCANTI; WALTER, 2008, p. 161). Além disso, a 
coleta de material biológico de espécies animais e vegetais para exploração ou a apropriação do conhecimento de uma comunidade, sem o consentimento prévio informado e uma negociação com a comunidade sobre a repartição dos benefícios, conforme rege a Convenção sobre Diversidade Biológica, é considerado Biopirataria, que aliada "à falta de fiscalização" e à "baixa diversidade de recursos naturais no restante do mundo", fazendo com que muitas indústrias estrangeiras se interessem por nossas riquezas, têm contribuído para a perda da diversidade biológica do nosso país (RIGDEN; CAVALCANTI; WALTER, 2008, p. 161).

Todavia, é relevante mencionar aos estudantes que é inegável que a tecnologia é também um facilitador da vida cotidiana, principalmente quando essa é utilizada no desenvolvimento de fármacos que são fabricados por meio da extração de um princípio ativo isolado ou na fabricação de fármacos sintéticos, os quais são fabricados quando determinada planta com propriedades farmacêuticas não mais se encontra disponível na forma in natura devido à exploração desenfreada ou até mesmo quando o princípio ativo foi desenvolvido em laboratório, simplesmente pelo fato de não estar disponível na natureza, sendo esses, indispensáveis no tratamento e na cura de certas doenças.

Dessa forma, é dever do professor tentar fazer um paralelo entre o desenvolvimento atual da ciência e suas tecnologias e o saber popular e/ou tradicional, a fim de que os estudantes percebam que as discussões realizadas em busca da construção de um novo saber escolar não têm a pretensão de direcionar a uma volta idílica ao tempo, mas, o que se pretende ao trazer tais discussões para o ambiente escolar é encontrar uma forma de se preservar a memória das comunidades detentoras de todo esse conhecimento empírico que foi construído com muito empenho, a fim de melhorar as condições de sobrevivência dessas e que são, até hoje, transmitidos durante gerações, ao mostrar que a escola é um local que pode contribuir muito para um ensino direcionado à realidade dos estudantes e, também, para que esses se sintam familiarizados ao compreender que a ciência está presente nas diversas atividades que executamos e situações que vivenciamos no nosso dia adia.

Assim sendo, autores como Xavier e Flôr (2015, p. 310) trazem, na concepção de Chassot (2006), Pinheiro e Giordan (2010) e Gondim e Mól (2007), que é "função da escola a valorização desse conhecimento e não se trata de uma supervalorização do saber popular, mas, sim, de reconhecer que esse conhecimento está presente na vida cotidiana de muitos alunos". Aliado a isso, Freire (1997) em suas palavras ainda destaca que "se não é possível defender uma prática educativa que se contente em girar em torno do "senso comum", também não é possível aceitar a prática educativa que, zerando o "saber de experiência feito", parta do conhecimento sistemático do(a) educador(a)" (p. 30-31). Todavia, ao tentar explorar novas possibilidades de ensino nas escolas, o professor ao se propor e se desafiar a trabalhar numa perspectiva diferenciada, trazendo para as discussões em sala de aula, o conhecimento prévio que o estudante já detém, por acreditar que tais experiências são valiosas no processo de ensino-aprendizagem, fazendo desse um subsídio para a construção do novo conhecimento escolar, estará contribuindo para desmistificar aquele ensino centrado em uma verdade absoluta quanto à forma de educação, que predomina na maioria das escolas e que é baseada somente no conhecimento científico que é apresentado nos livros didáticos, sendo esse, apenas reproduzido pela maioria dos professores. 
Em relação ao conhecimento científico, podemos dizer que é aquele que foi produzido por meio da investigação e do aprimoramento dos conhecimentos do senso comum. Passível de ser demonstrado e comprovado, tal conhecimento foi elaborado com o objetivo de conceituar fatos como sendo verdadeiros e passíveis de serem submetidos a testes de falseabilidade. Contudo, "o conhecimento científico apresenta um caráter provisório uma vez que pode ser continuamente testado, enriquecido e reformulado" (FONSECA, 2002, p. 10).

Conforme Baptista (2010), o ensino de Ciências para sociedades tradicionais precisa estar voltado à demarcação dos saberes, para que os estudantes compreendam que existem outras formas de explicação da natureza, além daquelas que fazem parte do seu dia a dia, pois, dessa forma, por meio do diálogo, será possível desenvolver neles "a consciência crítica, a autonomia, a emancipação e a valorização das suas culturas" (p. 690), sem perder a essência das suas concepções prévias de mundo, ao mesmo tempo em que se tornem aptos a ampliar os seus universos de conhecimentos com concepções científicas e que se tornem capazes de compreendê-los, além de "tê-los como válidos e verdadeiros em suas vidas" (p. 681).

Dessa forma, ao se deparar com alunos provenientes de comunidades tradicionais, o professor precisa estar atento a essas especificidades para que consiga ministrar e direcionar a aula de acordo com as particularidades da classe, considerando o meio que esses indivíduos vivem, de modo a facilitar a comunicação e a compreensão da ciência em tais espaços, pois, do contrário, o professor estará conduzindo "os estudantes a conflitos entre as explicações científicas e as explicações oriundas dos seus meios socioculturais" (BAPTISTA, 2010, p. 681), contribuindo para a anulação dos saberes que foram construídos empiricamente e transmitidos oralmente de geração em geração.

Além disso, é oportuno mencionar que, quando o ensino de Ciências for direcionado especificamente para as escolas indígenas, as quais, Perrelli (2008) define como sendo um "espaço de pesquisar, ensinar e aprender as suas próprias tradições" e que também precisa ser um "lugar de acesso aos conhecimentos produzidos por outras sociedades tradicionais e pela ciência ocidental" (p. 382), fica evidente a importância da "abertura do currículo a outras expressões culturais, a outros tipos de conhecimentos e de estilos de ensino e aprendizagem, como instrumento de empoderamento das culturas silenciadas" (p. 383), bem como o papel do professor como mediador responsável por fazer esse elo entre tais conhecimentos, aliado à inovação de práticas pedagógicas orientadas e que respeitem as diferenças e os estilos de aprendizagem. Dessa forma, acredita-se que a escola irá contribuir para a aquisição do saber, a promoção da autonomia e a participação dos povos indígenas na construção de um permanente diálogo com as diferentes sociedades.

Sendo assim, nesta pesquisa, diante das leituras que foram feitas e considerando as especificidades dos sujeitos envolvidos, adere-se a autores considerando a importância e o significado dado tanto para os saberes populares quanto para os conhecimentos tradicionais.

Desse modo, em concordância com os autores citados, passamos a entender os saberes populares como sendo o resultado da produção de conhecimentos práticos, oriundos da vivência e sobrevivência de grupos periféricos, ou seja, das camadas menos privilegiadas da sociedade seja do ponto de vista social, econômico ou cultural.

Em contrapartida, passamos a entender os conhecimentos tradicionais como sendo o resultado da produção de conhecimentos práticos, também oriundos da vivência e 
sobrevivência, transmitidos oralmente de geração em geração, quando direcionados a comunidades específicas, como as indígenas, as quais apresentam uma estreita relação com a natureza e que se apropriam desses meios para obter as condições necessárias para a manutenção da vida dentro de tais comunidades.

Entretanto, ao considerar que o saber popular e/ou conhecimento tradicional das comunidades vem se perdendo nos últimos anos, principalmente entre os jovens, e que tais conhecimentos podem ser utilizados como recurso didático nas escolas, para despertar o interesse dos estudantes, a fim de torná-los mais críticos e reflexivos, Medeiros (2013), considera a possibilidade de utilizar o tema "Plantas Medicinais" como objeto de estudo, contribuindo também para a compreensão dos conteúdos que acabam sendo transmitidos de forma descontextualizada.

De acordo com Mendes (2015), outros motivos também têm contribuído para a diminuição da prática do uso de plantas medicinais nas aldeias, a saber: o aumento da procura e oferta de medicamentos no posto de saúde, que vem desestimulando a busca das ervas no mato. O aumento das lavouras e o uso indiscriminado de agrotóxicos também têm contribuído para a diminuição de muitas espécies vegetais que eram de extrema importância para o tratamento de doenças. Em relação ao surgimento de novas religiões, muitos indígenas optaram por se converter, deixando de lado o uso das plantas medicinais.

Para Fortunato (2014, p. 16), de acordo com as pessoas mais velhas da comunidade, o que têm influenciado bastante no baixo índice do uso das plantas medicinais (VẼNHKAGTA) é a medicina do não indígena. Ainda, de acordo com o autor, "na comunidade, em geral, o que tem sido mais praticado ou usado é os remédios do posto/farmácia, enquanto que o mais valorizado pelos mais velhos é as plantas medicinais". Já em relação aos mais jovens da comunidade, "o caminho para o tratamento de qualquer doença é ir a um posto de saúde buscar os remédios, que são bons para sua dor ou doenças". Além disso, a maioria das pessoas já possui algum medicamento em casa, para o caso de alguma emergência que possa vir a ocorrer, à noite, finais de semana ou feriados, que são horários em que a Unidade Básica de Saúde não fornece atendimento à comunidade.

Tais informações, quando aliadas ao avanço das tecnologias, têm contribuído para o aumento do desinteresse dos jovens em aprender sobre o conhecimento e o uso das plantas medicinais para o tratamento de doenças e isso é um dos fatores que evidencia a necessidade de trabalhar em busca da valorização do conhecimento tradicional, o qual faz parte da sabedoria empírica dessas comunidades, as quais possuem características próprias de sobrevivência, a fim de preservar a memória de um povo que faz parte da história da humanidade (MENDES, 2015).

Segundo Mendes (2015), durante a realização de sua pesquisa que buscou analisar os usos das ervas medicinais no cotidiano Kaingang da aldeia Pinhalzinho, Terra Indígena Chapecó-RS, verificou por meio de conversas informais com os mais jovens, que o uso dessas vem sendo influenciado, dentre outros fatores, pelo fácil acesso aos medicamentos industrializados.

Por conta disso, diante das discussões realizadas sobre a perda do costume quanto ao uso das plantas medicinais no tratamento de doenças e da importância da valorização do conhecimento tradicional sobre o uso de tais plantas entre os jovens das comunidades ao considerar que em muitas dessas localidades, "o uso das ervas é o principal recurso para o tratamento de diversas doenças, além de trazer uma grande economia para as famílias" (KOVALSKI; OBARA, 2013, p. 912), uma possibilidade seria por meio da utilização das plantas 
medicinais no ensino de Ciências, a partir de "estratégias e metodologias de ensino que visam resgatar o conhecimento tradicional, num processo de diálogo com o saber científico", sendo essa, uma condição fundamental em relação "a valorização da cultura popular e tradicional dos envolvidos" (p. 913), ou, até mesmo, por meio da realização de oficinas que poderiam ocorrer tanto nas escolas como em outros espaços da comunidade (BENTO, 2015).

Ainda de acordo com Kovalski e Obara (2013), "a valorização do conhecimento popular que os alunos trazem sobre as plantas medicinais potencializa o interesse destes sobre os conhecimentos científicos a serem trabalhados sobre o tema" (p. 911), sendo que, na maioria das vezes, o estudo e a compreensão de conceitos sobre as plantas acabam despercebidos pelos estudantes, ao serem simplesmente transmitidos pelo estudo do livro didático. Além disso, o professor poderá se utilizar de tal prática para enfatizar a questão do uso racional de tais plantas, sendo que muitas destas "apresentam toxicidade elevada e precisam ser utilizadas de maneira correta, de preferência com acompanhamento médico" (p. 912).

Todavia, isso não significa "que o conhecimento científico deva ser substituído nas salas de aula pelo conhecimento etnocientífico, mas utilizar desse conhecimento (popular) como uma ferramenta de mobilização cognitiva e afetiva do aluno para a percepção do novo conhecimento curricular que se the apresenta: o científico" (COSTA, 2008, p. 165). Além disso, o que se pretende por meio do contato com a realidade social dos alunos é que os professores reconheçam que os "saberes populares" são uma ferramenta valiosa para que de fato o processo de ensino-aprendizagem flua naturalmente.

Em relação à Ciência, é notável que, frequentemente, o ensino vem sendo ministrado de uma forma mecânica, contribuindo para a falta de entendimento do conteúdo por parte dos alunos, os quais acabam se desinteressando pela disciplina, a qual é apenas transmitida sem ter nenhuma ligação às situações do seu dia a dia. Contudo, é importante considerar que muitas das nossas escolas atendem estudantes provenientes de classes mais populares e até mesmo de comunidades tradicionais, e trazem consigo um saber popular/conhecimento tradicional em relação à "medicina caseira, que foi se acumulando ao longo do tempo passando de pais para filhos", (MEDEIROS, 2013, p. 5) o qual poderá ser considerado no planejamento didático do professor, contribuindo para um melhor aprendizado dos alunos, tanto da ciência no geral, como da botânica em específico, e também os tornando capazes de "construir conhecimentos sobre plantas medicinais mais próximos do conhecimento científico que do senso comum" (MEDEIROS, 2013, p. 10).

Diante disso, ressalta-se a importância de utilizar no contexto educativo abordagens metodológicas que permitam aos estudantes valorizar seus conhecimentos prévios e que estejam vinculados a sua cultura. Essa aproximação permite a eles dar sentido ao objeto do conhecimento e ao mesmo tempo reconhecer seu valor frente às situações vivenciais. De forma mais especifica, identifica-se essa concepção de ensino frente as plantas medicinais que, ao mesmo tempo que possibilita conhecimentos específicos das Ciências/Biologia, possibilita valorizar a cultura.

\section{Percurso metodológico}

O estudo desenvolvido é de natureza qualitativa, e de acordo com Minayo, Deslandes e Gomes (2012), o viés qualitativo se caracteriza por trabalhar com o universo dos significados, das aspirações, dos motivos, das crenças, dos valores e das atitudes. Nela, o ser 
humano é entendido como parte da realidade social, devido à sua forma de agir, pensar e interpretar suas ações, a partir da realidade. O objeto de estudo da pesquisa qualitativa, dificilmente, poderá ser traduzido em números, já que busca responder questões muito particulares.

Com o objetivo de avaliar os conhecimentos prévios dos alunos e selecionar as plantas medicinais que iriam fazer parte do presente estudo, foi aplicado um questionário misto nos anos finais do Ensino Fundamental de uma Escola Estadual Indígena, localizada no interior do Rio Grande do Sul.

O público-alvo do estudo foi composto por 49 estudantes indígenas que estavam frequentando a escola. A aplicação desse instrumento ocorreu durante as aulas de Ciências, pela professora pesquisadora (primeira autora) que estava atuando na escola no período do estudo (2019).

O questionário aplicado versava basicamente sobre o conhecimento sobre plantas medicinais dos estudantes indígenas. A partir das respostas apresentadas, elencaram-se seis plantas medicinais que foram analisadas quanto às possibilidades de abordagens de conceitos/conteúdos de Ciências à luz da BNCC, com relação as unidades temáticas, os objetos do conhecimento e as habilidades vinculadas.

\section{Análise dos resultados}

Ao analisar as respostas do questionário que foi respondido por 49 estudantes indígenas, constatou-se que $91 \%$ dos estudantes afirmaram conhecer algum tipo de planta medicinal. Além disso, todos os envolvidos afirmaram acreditar na capacidade das plantas medicinais com relação ao auxílio ao tratamento de doenças.

Uma das questões versou sobre a transmissão dos conhecimentos sobre plantas medicinais. Observou-se que acima de $70 \%$ dos estudantes afirmaram que o conhecimento acerca de plantas medicinais que eles possuíam foi adquirido por meio de seus pais e/ ou familiares.

Com relação ao fato de o conhecimento tradicional sobre plantas medicinais estar sendo repassado e utilizado pelos os jovens da comunidade, observou-se que $12,24 \%$ dos estudantes concordaram com esta afirmação e 18,37\% dos estudantes não concordaram, ou seja, não acreditam que o conhecimento sobre plantas medicinais está sendo repassado e utilizado pelos jovens da comunidade.

Outro aspecto a ser destacado é que, dos 49 questionários que foram respondidos, 61,25\% dos estudantes acreditam que "um pouco" do conhecimento sobre plantas medicinais está sendo repassado e utilizado pelos jovens da comunidade e ainda, um pequeno número de estudantes, 8,16\% preferiu não responder.

Nesse viés, os resultados apresentados por Emiliano (2015) se assemelham aos resultados deste estudo, na medida em que o autor concluiu que houve um abandono e a falta de valorização dos saberes e práticas relacionadas com a Educação Ambiental, ainda que a maioria dos entrevistados soubesse identificar as plantas medicinais apresentadas bem como a indicação de uso medicinal.

O conhecimento das propriedades medicinais das plantas é uma das maiores riquezas da cultura indígena, uma sabedoria tradicional que passa de geração em geração, pois vivendo em permanente contato com a natureza, os índios estão habituados a estabelecer 
relações de semelhança entre as características de certas substâncias naturais e seu próprio corpo.

\begin{tabular}{|c|c|c|c|c|}
\hline & Ano & Conteúdos & \multirow{2}{*}{$\begin{array}{l}\text { UT - OC } \\
\text { olução - Célula como } \\
\text { ida }\end{array}$} & \multirow{2}{*}{$\begin{array}{l}\text { Habilidades } \\
\text { (EF06CI05) } \\
\text { (EF06CI06) }\end{array}$} \\
\hline \multirow{8}{*}{ 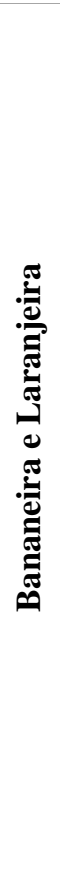 } & \multirow{4}{*}{$6^{\mathbf{0}}$} & $\begin{array}{l}\text { Célula Vegetal; Os níveis de } \\
\text { organização dos seres vivos (tecidos } \\
\text { vegetais). }\end{array}$ & & \\
\hline & & $\begin{array}{l}\text { Transformação química nos } \\
\text { alimentos. }\end{array}$ & $\begin{array}{l}\text { Matéria e energia - Transformações } \\
\text { químicas }\end{array}$ & (EF06CI02) \\
\hline & & $\begin{array}{l}\text { Tecnologia e alimentação: aditivos } \\
\text { químicos nos alimentos. }\end{array}$ & $\begin{array}{l}\text { Matéria e energia - Materiais } \\
\text { sintéticos }\end{array}$ & (EF06CI04) \\
\hline & & $\begin{array}{l}\text { Métodos separação de misturas: } \\
\text { catação, filtração, destilação por } \\
\text { arraste à vapor, extração por solvente. }\end{array}$ & $\begin{array}{l}\text { Matéria e energia - Separação de } \\
\text { materiais }\end{array}$ & (EF06CI03) \\
\hline & & $\begin{array}{l}\text { Classificação filogenética dos } \\
\text { vegetais (taxonomia). }\end{array}$ & $\begin{array}{l}\text { Vida e evolução - Diversidade de } \\
\text { ecossistemas }\end{array}$ & (EF07CI07) \\
\hline & $7^{\circ}$ & $\begin{array}{l}\text { Alimentação Saudável: carboidratos, } \\
\text { lipídios, proteínas, vitaminas e sais } \\
\text { minerais. }\end{array}$ & $\begin{array}{l}\text { Vida e evolução - Programas e } \\
\text { indicadores de saúde pública }\end{array}$ & (EF07CI09) \\
\hline & $8^{\mathbf{o}}$ & $\begin{array}{l}\text { Angiospermas: raiz, caule, folha, flor, } \\
\text { fruto e semente; Reprodução } \\
\text { assexuada; Reprodução sexuada. }\end{array}$ & $\begin{array}{l}\text { Vida e evolução - Mecanismos } \\
\text { reprodutivos }\end{array}$ & (EF08CI07) \\
\hline & $9^{\circ}$ & Função Inorgânica: ácido e base. & $\begin{array}{l}\text { Matéria e energia - Aspectos } \\
\text { quantitativos das transformações } \\
\text { Químicas. }\end{array}$ & (EF09CI02) \\
\hline & $6^{\mathbf{0}}$ & Biodiversidade & $\begin{array}{l}\text { Terra e universo - Forma, estrutura e } \\
\text { movimentos da Terra }\end{array}$ & (EF06CI11) \\
\hline 苞 & & Biomas & $\begin{array}{l}\text { Vida e evolução - Diversidade de } \\
\text { ecossistemas }\end{array}$ & (EF07CI07) \\
\hline$\frac{1}{0}$ & $7^{\circ}$ & Biodiversidade & $\begin{array}{l}\text { Vida e evolução - Diversidade de } \\
\text { ecossistemas }\end{array}$ & (EF07CI08) \\
\hline 可 & $8^{\circ}$ & Gimnospermas & $\begin{array}{l}\text { Vida e evolução - Mecanismos } \\
\text { reprodutivos }\end{array}$ & (EF08CI07) \\
\hline & $9^{\circ}$ & Biodiversidade & $\begin{array}{l}\text { Vida e evolução - Preservação da } \\
\text { biodiversidade }\end{array}$ & $\begin{array}{l}\text { (EF09CI12) } \\
(\text { EF09CI13) }\end{array}$ \\
\hline$\frac{\pi}{3}$ & & Sistema sensorial & $\begin{array}{l}\text { Vida e evolução - Interação entre os } \\
\text { sistemas locomotor e nervoso }\end{array}$ & $\begin{array}{l}\text { (EF06CI07) } \\
(\mathrm{EF06CI08)}\end{array}$ \\
\hline 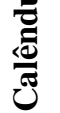 & $6^{0}$ & $\begin{array}{l}\text { Estados físicos da matéria; Mudança } \\
\text { de estado físico da matéria. }\end{array}$ & $\begin{array}{l}\text { Terra e universo - Forma, estrutura e } \\
\text { movimentos da Terra }\end{array}$ & (EF06CI11) \\
\hline$\stackrel{0}{\stackrel{0}{\overparen{E}}}$ & & $\begin{array}{l}\text { Propriedades específicas dos } \\
\text { materiais; Substâncias puras e } \\
\text { misturas. }\end{array}$ & $\begin{array}{l}\text { Matéria e energia - Misturas } \\
\text { homogêneas e heterogêneas }\end{array}$ & (EF06CI01) \\
\hline$\underbrace{\Xi}$ & $9^{\circ}$ & $\begin{array}{l}\text { Estados físicos da matéria; Mudança } \\
\text { de estado físico da matéria. }\end{array}$ & $\begin{array}{l}\text { Matéria e energia - Estrutura da } \\
\text { matéria }\end{array}$ & $\begin{array}{l}\text { (EF09CI01) } \\
\text { (EF09CI03) }\end{array}$ \\
\hline & & Saneamento básico; Dengue & $\begin{array}{l}\text { Vida e evolução - Programas e } \\
\text { indicadores de saúde pública }\end{array}$ & $\begin{array}{l}\text { (EF07CI09) } \\
\text { (EF07CI10) }\end{array}$ \\
\hline 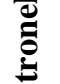 & $7^{\circ}$ & Difusão dos gases & $\begin{array}{l}\text { Matéria e energia - Formas de } \\
\text { propagação do calor }\end{array}$ & (EF07CI02) \\
\hline$\dot{U}$ & $\mathbf{9}^{\mathbf{0}}$ & Difusão dos gases & $\begin{array}{l}\text { Matéria e energia - Estrutura da } \\
\text { matéria }\end{array}$ & $\begin{array}{l}\text { (EF09CI01) } \\
\text { (EF09CI03) }\end{array}$ \\
\hline
\end{tabular}

Quadro 1 - Relação entre os conteúdos e as unidades temáticas (UT), objetos de conhecimento (OC) e habilidades da BNCC para as seis plantas medicinais. Fonte: da pesquisa, 2021. 
A partir dessas respostas apresentadas sobre o conhecimento quanto às plantas medicinais (conhecer ou não conhecer), elencaram-se seis plantas medicinais, a saber: bananeira, laranjeira, pinheiro-do-paraná, camomila, calêndula e citronela.

A escolha das seis plantas medicinais se deu, primeiramente, pelos conhecimentos que os alunos apresentaram sobre elas, ou seja, elencaram-se as plantas que eles apresentaram um conhecimento maior que $60 \%$ nas respostas do questionário. Em segundo momento, a escolha foi conduzida pelas possibilidades de abordagens de conceitos/conteúdos de Ciências. Procedeu-se, então uma análise à luz da BNCC, no sentido de apresentar quais seriam as unidades temáticas, os objetos do conhecimento e as habilidades vinculadas.

\begin{tabular}{|c|c|}
\hline & onadas \\
\hline 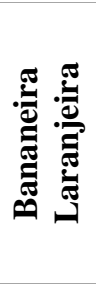 & $\begin{array}{l}\text { Aula prática: Identificar as células macroscópicas da bainha da folha da bananeira a olho nu; } \\
\text { Elaboração de um cartaz da célula vegetal; Aula prática: Visualizar as glândulas translúcidas da } \\
\text { face abaxial da folha de laranjeira; Pesquisa sobre o uso da madeira na região; Atividade Prática: } \\
\text { Visualizar os alvéolos do endocarpo da laranja; Desvendando a Diversidade dos Seres Vivos e os } \\
\text { Segredos dos Nomes Científicos; Atividade prática: Tatuagem na Banana; Salada de fruta } \\
\text { (banana e laranja); Cristais de laranja; Atividade prática: Suco de laranja; Atividade prática: } \\
\text { Prensagem a frio da casca de laranja; Atividade prática: Laranja em chamas. }\end{array}$ \\
\hline 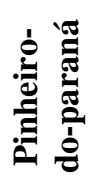 & $\begin{array}{l}\text { Atividade prática: Identificar os órgãos vegetativos e } \\
\text { Atividade sobre o texto: Kamë e Kajru: a dualidade fé }\end{array}$ \\
\hline & $\begin{array}{l}\text { momila com/sem açúcar; Atividade Prática: Simulando os estados físicos da matéria; Atividade } \\
\text { ática: Simulando a solubilidade; Atividade prática: Confecção de sabão medicinal de } \\
\text { momila; Atividade prática: Confecção de uma pomada medicinal de Calêndula; - Plantar } \\
\text { udas de calêndula no jardim da escola. }\end{array}$ \\
\hline & $\begin{array}{l}\text { idade prática: Identificação de focos da dengue, por meio de uma caminhada com os } \\
\text { dantes pela comunidade ou locais próximos à escola; Atividade prática: Confecção de um } \\
\text { lente natural de citronela; Atividade prática: Plantar mudas de citronela no jardim/horta da } \\
\text { la. }\end{array}$ \\
\hline
\end{tabular}

Quadro 2 - Relação de atividades que podem ser desenvolvidas envolvendo as seis plantas medicinais. Fonte: da pesquisa, 2021.

A BNCC menciona que para fins de para "garantir o desenvolvimento das competências específicas, cada componente curricular apresenta um conjunto de habilidades" (BRASIL, 2017, p. 28). Tais habilidades "expressam as aprendizagens essenciais que devem ser asseguradas aos alunos nos diferentes contextos escolares" (p. 29) e estão vinculadas a distintos objetos do conhecimento que são compreendidos na forma de conteúdos, conceitos e processos, sendo sistematizados em unidades temáticas. No que compete à área das Ciências da Natureza, existem três unidades temáticas, para o Ensino Fundamental: Matéria e energia, Vida e Evolução e Terra e Universo. De acordo com a BNCC:

Essas três unidades temáticas devem ser consideradas sob a perspectiva da continuidade das aprendizagens e da integração com seus objetos de conhecimento ao longo dos anos de escolarização. Portanto, é fundamental que elas não se desenvolvam isoladamente (BRASIL, 2017, p. 329). 
Nesse sentido, apresenta-se de uma forma bastante ampla os conceitos/conteúdos de Ciências relacionados às seis plantas medicinais que foram elencadas neste estudo. 0 Quadro 1 apresenta uma relação dos conceitos/conteúdos que podem ser abordados durante as aulas de Ciências nas séries finais do Ensino Fundamental, em cada uma das plantas medicinais elencadas, no sentido de apresentar quais seriam as unidades temáticas (UT), os objetos do conhecimento (OC) e as habilidades vinculadas. O Quadro 2 elucidada algumas sugestões de atividades que podem vir a ser desenvolvidas envolvendo as plantas medicinais elencadas.

Sendo assim, a ideia de valorizar os saberes populares, trazendo-os para as salas de aula, por intermédio do ensino de Ciências, conforme era apontado por Chassot (2008), é algo possível, e que encontra respaldo na BNCC. Contudo, como o autor destaca, é importante que o conhecimento seja construído de forma contextualizada, por meio do diálogo entre esses saberes populares e as metodologias de ensino utilizadas.

Nesse modelo de educação tradicional, o currículo escolar precisa ser pensado e elaborado de acordo com as necessidades dos estudantes, pois, a partir do momento em que o professor conseguir fazer essa ligação entre os conteúdos escolares e a realidade dos estudantes, esses passarão a ter significado, tornando-se um importante instrumento para a compreensão de questões pertinentes à realidade de seu povo (RCNEI, 1988).

Os conhecimentos aprendidos pelos estudantes integrantes de uma comunidade, quando partem de sua realidade, como no caso das plantas medicinais, são saberes que fazem parte da vivência desses sujeitos, e que quando incorporado no ensino de Ciências da Natureza poderá propiciar uma aprendizagem com mais significado, uma vez que esses sujeitos estão inseridos dentro desse contexto.

\section{Considerações finais}

As plantas medicinais são conhecidas por terem um papel muito importante na cura e no tratamento de algumas doenças. No passado, consideradas como o único recurso terapêutico de muitas comunidades tradicionais, tais plantas representavam uma importante ferramenta na promoção da saúde. Para muitas comunidades indígenas, as quais mantêm uma estreita relação com a natureza, essas plantas, ainda hoje, podem ser a única alternativa para o tratamento e a cura de muitas doenças. Além disso, no Brasil, muitas famílias carentes e que residem em locais distantes do atendimento médico se utilizam de tais recursos, sendo essa, uma das alternativas mais viáveis ao tratamento das mais diversas enfermidades a que são acometidos.

Em relação ao uso das plantas medicinais, esse se dá tanto pelo saber popular pelas classes menos favorecidas quanto pelo conhecimento tradicional, o qual ocorre em sociedades tradicionais, dentre elas, as indígenas, por meio da transmissão oral entre as gerações, ou seja, pelo contato direto dos mais velhos com os mais novos, quando crianças e jovens deveriam acompanhar seus pais e familiares na realização de tarefas cotidianas relacionadas ao conhecimento e uso de tais plantas com finalidade terapêutica, sem o acompanhamento de instituições de ensino. Contudo, muitos estudos têm evidenciado que o conhecimento e o uso das plantas medicinais nas comunidades indígenas mais próximas do meio urbano vêm se perdendo, principalmente entre os mais jovens da comunidade, sendo que esses preferem utilizar os medicamentos industrializados, por diversos motivos. 
Um dos principais motivos que contribui para o uso dos medicamentos industrializados pelos jovens com maior frequência é o fácil acesso, pois, basta apenas ir até o posto de saúde, consultar e pegar o remédio, sendo que muitas vezes, dependendo da situação, não precisa nem de receita, como é o caso dos analgésicos, antiespasmódicos e antitérmicos, os quais podem ser dispensados pelo farmacêutico responsável ou por outro profissional de saúde que ali se encontra.

Outro motivo que contribui para a falta de interesse em relação ao conhecimento e ao uso das plantas medicinais pelos jovens tem sido o acesso aos meios de comunicação, principalmente o telefone celular. Esses eletrônicos despertam o interesse dos jovens de uma forma tão contagiante, que acabam "roubando" a maior parte do tempo em que eles poderiam estar aprendendo sobre as plantas medicinais, com as pessoas da família ou da própria comunidade no horário disponível em que não estão na escola.

Diante dessa situação e das informações que foram obtidas durante o período de investigação, acredita-se na necessidade da valorização do conhecimento a respeito das plantas medicinais entre os jovens das comunidades. Além disso, entendemos que a escola é um espaço ideal para se tentar trabalhar a revitalização desses saberes que os alunos trazem empiricamente sobre tal assunto, por meio de conceitos/conteúdos no ensino de Ciências.

Além de promover a valorização dos conhecimentos tradicionais indígenas por meio das plantas medicinais, visando ao fortalecimento de suas identidades, acredita-se que trabalhar tendo como objeto de estudo o tema "Plantas Medicinais", por meio de conceitos/conteúdos no ensino de Ciências, irá contribuir para potencializar o interesse dos alunos sobre os conhecimentos científicos que também precisam ser discutidos nessas escolas, por meio de uma aula de qualidade em que os alunos consigam ver sentido naquilo que estão aprendendo.

A intenção de trabalhar nessa perspectiva, fazendo um paralelo entre o conhecimento tradicional e o conhecimento científico, é de que o aluno entenda a diferença que existe entre esses conhecimentos e, a partir disso, consiga dar sentido aos saberes escolares, que, na maioria das vezes, acabam sendo transmitidos, como se estivessem prontos e acabados, tornando a aula repetitiva e desmotivadora.

Por fim, tem-se que a intenção de identificar quais as potencialidades do saber popular e/ou conhecimento tradicional para abordar e discutir os conceitos/conteúdos de Ciências da Natureza, nas séries finais do Ensino Fundamental, encontra respaldo na BNCC sendo que é possível desenvolver habilidades por meio da valorização da realidade em que os alunos estão inseridos.

\section{Referências}

BAPTISTA, Geilsa C. S. Importância da demarcação de saberes no ensino de ciências para as sociedades tradicionais. Ciência \& Educação, v.16, n. 3, p. 679-694, 2010.

BASTOS, Sandra N. D. Etnociências na sala de aula: uma possibilidade para aprendizagem significativa. In: XI Congresso nacional de educação. Educere. Curitiba: PUC. 2013. Anais.

BENTO, Armandio K. Kujá e suas ervas medicinais. Trabalho de conclusão de curso. Universidade Federal de Santa Catarina, Trindade, SC, 2015. 
BRASIL. Decreto n 6.040, de 7 de Fevereiro de 2007. Institui a Política Nacional de Desenvolvimento Sustentável dos Povos e Comunidades Tradicionais.

BRASIL. Base Nacional Comum Curricular. Educação é a base. Ministério da Educação. Brasília: MEC, 2017.

CHASSOT, Áttico I. Alfabetização científica: questões e desafios para a educação. 2. ed. ljuí: Ed. Universidade Regional do Noroeste do Estado do Rio Grande do Sul, 2001. 438 p. (Educação em química).

CHASSOT, Áttico I. Alfabetização Científica: uma possibilidade para a inclusão social. Revista Brasileira de Educação. n. 22, p. 89-100, 2003.

CHASSOT, Áttico I. Fazendo Educação em Ciências em um Curso de Pedagogia com Inclusão de Saberes Populares no Currículo. Química Nova na Escola. n. 27, fev. 2008.

COSTA, Ronaldo G. de A. Os Saberes Populares da Etnociência no Ensino das Ciências Naturais: uma proposta didática para aprendizagem significativa. Revista Didática Sistêmica, v. 8. jul./dez. 2008.

DIAS, Braulio F. S. (Org.). A Convenção sobre Diversidade Biológica - CDB. Ministério do Meio Ambiente - MMA. Brasília - DF. 2000.

DIEGUES, Antônio C.; ARRUDA, Rinaldo S. V.; SILVA, Viviane C. F. da; FIGOLS, Francisca A. B.; ANDRADE, Daniela. Biodiversidade e Comunidades Tradicionais no Brasil. São Paulo: USP, 1999.

EMILIANO, Darci. Revitalização dos Saberes e Práticas Kaingang sobre as Plantas Tradicionais como proposta de Educação Ambiental na Terra Indígena Ligeiro. 2015. Dissertação

(Mestrado em Educação Ambiental) - Programa de Pós-Graduação em Educação Ambiental - PPGEA, Universidade Federal do Rio Grande - FURG, Rio Grande. 2015.

FIGARO, Anajara K. O Ensino de Química e Seminário Integrado: valorizando a pesquisa do estudante a respeito dos saberes populares das plantas medicinais. Dissertação (Mestrado em Ensino de Ciências) - Programa de Pós-Graduação Stricto Sensu em Ensino de Ciências, Universidade Federal do Pampa, Bagé. 2015.

FONSECA, João J. S. da. Metodologia da pesquisa científica. Fortaleza: UECE, 2002. Apostila. FREIRE, Paulo. Pedagogia do Oprimido. 17. ed. Rio de Janeiro: Paz e Terra. 1987.

FREIRE, Paulo. Pedagogia da esperança: um reencontro com a pedagogia do oprimido. Rio de Janeiro: Paz e Terra, 1997. 245 p.

GONDIM, Maria S. da C.; MÓL, Gerson de S. Interlocução entre os saberes: relações entre os saberes populares de artesãs do triângulo mineiro e o ensino de ciências. In: Encontro Nacional de Pesquisa em Educação em Ciências, 7, 2009, Florianópolis. Anais.

KOVALSKI, Mara L.; OBARA, Ana T. O Estudo da Etnobotânica das Plantas Medicinais na Escola. Ciênc. Educ., Bauru, v. 19, n. 4, p. 911-927, 2013.

LOPES, Alice R. C. Reflexões sobre currículo: as relações entre senso comum, saber popular e saber escolar. Em Aberto, Brasília, n. 58, p. 14-23, abr./jun. 1993. 
MEDEIROS, Edilmari T. de O. A Importância da Aprendizagem das Plantas Medicinais no Ensino da Botânica. Os desafios da Escola Pública Paranaense na Perspectiva do Professor PDE. Universidade Estadual do Centro Oeste - Unicentro. Pato Branco - PR, 2013. v. 1.

MENDES, Ivania. O uso das Ervas Medicinais na atualidade Kaingang da Terra Indígena Xapecó, Santa Catarina, Brasil. Trabalho apresentado à Universidade Federal de Santa Catarina, para a conclusão do Curso de Graduação em Licenciatura Intercultural Indígena do Sul da Mata Atlântica. Florianópolis - SC. Fevereiro, 2015.

MINAYO, Maria C. de S.a; DESLANDES, Suely F.; GOMES, Romeu. Pesquisa social: teoria, método e criatividade. 31. ed. Petrópolis: Vozes, 2012. 108 p.

PERRELLI, Maria A. de S. "Conhecimento Tradicional" e currículo multicultural: notas com base em uma experiência com estudantes indígenas kaiowá/guarani. Ciência \& Educação, v. 14, n. 3, p. 381-96, 2008.

RCNEI. Referencial curricular nacional para as escolas indígenas. Ministério da Educação e do Desporto. Secretaria de Educação Fundamental. Brasília: MEC/SEF, 1998.

RIGDEN, Luciane V. de M.; CAVALCANTI, Taciana B.; WALTER, Bruno M. T. A conservação e a utilização de recursos genéticos vegetais. In: BENSUSAN, Nurit (org.). Seria melhor mandar ladrilhar? Biodiversidade: como, para que e por quê. 2. ed. São Paulo: Peirópolis; Brasília: Editora Universidade de Brasília, 2008. 428 p.

SANTILLI, Juliana. A biodiversidade e os povos tradicionais. In: BENSUSAN, Nurit (org.). Seria melhor mandar ladrilhar? Biodiversidade: como, para que e por quê. 2. ed. São Paulo: Petrópolis; Brasília: Editora Universidade de Brasília, 2008. 428 p.

VENQUIARUTO, Luciana D.; DALLAGO, Rogério M.; VANZETO, Jenifer; DEL PINO, José Claudio. Saberes Populares Fazendo-se Saberes Escolares: Um Estudo Envolvendo a Produção Artesanal do Pão. Química e Sociedade. Química Nova na Escola, v. 33, n. 3, 2011.

XAVIER, Patrícia M. A.; FLÔR, Cristhiane C. C. Saberes Populares e Educação Científica: um olhar a partir da literatura na área de ensino de ciências. Revista Ensaio. Belo Horizonte. v. 17, n. 2, p. 308-328, 2015. 